\title{
Bring the Culture Back in: Institutional Embeddedness between Neo-Confucianism and Patriarchy in Policy Making of Taiwan
}

\author{
Tsai-Chuan Ma \\ Associate Professor \\ The Department of Labour Relations, National Chung Cheng University \\ Minghsiung 62102, Taiwan \\ Tel: 886-5-272-0411 ext.3205Ｅ-mail: labtma@ccu.edu.tw
}

This paper was presented in the Annual Conference of 2003 ASA (American Sociological Association). Many thanks for suggestions from discussants were helpful in the revising work.

\begin{abstract}
Following the discussions of Giddens $(1979,1984)$ and Archer (1993), the dual discussions between agency/structure and culture/structure had been seen as the centrality context of analytical unit in a modern society. Whereas, the structure and the culture interweave and penetrate within the social-political system, as well as exist is relatively autonomous form one another. Furthermore, some culture theorists recognize culture as the means by which orderliness patterned relations are maintained in a society and they tend to be concerned with the symbolic that is social norms and values shared in the cognitive and active structure. This paper wants to argue and reexamine the claim of "cultural theory" which believes a theory of culture must create measures of culture that allow the space for the comparisons across time and space, and relative values to embed into social relations and institutions. In addition, this paper indicates the particular cultural factors and provides the power of explanation in the construction of policymaking circumstance and active system of social behavior. Overall, the cultural factor becomes a potential promoter in the process of policymaking. By the discussion of the articulation between Neo-Confucianism thought (top-down system) and the patriarchal system (bottom-up system), this paper provides why and how the articulation effects to formulate a strained potential control and structural shape different policy manipulations and interactive constructions in the policymaking process of Taiwan. The specific dual system constructs the transmission of cultural shadow to influence the policy outcomes.
\end{abstract}

Keywords: Relatively autonomous form, Cultural theory, Neo-Confucianism thought, The Patriarchal system

\section{Introduction}

The argument of this paper concerns the way that internal mechanisms may influence divergent paths of policy formulation and development, which become different models, such as contentious, coordinated or collaborative, within the policymaking process. Overall, the social construction and political interaction of all objects of the policy domain will be affected by cultural factors. This prominent influence becomes my emphasis in this paper which will demonstrate how cultural factors shape different dimensions within policy decision-making and how culture can create a historical context, and can then play a prominent role in the process of policy formulation. In the cultural dimension, Swidler (1987) has demonstrated how cultural structures also constrain actors by preventing certain arguments from being articulated in public discourse or, once articulated, from being favourably interpreted by others or even properly understood. In this paper attempts to bring the influence of cultural factors back in the systematic investigation of the labor policy of Taiwan, and to clarify further the specific cultural factors which influence the process of policymaking in Taiwan. Ordinarily, it is difficult to investigate the overt relationship between cultural factors and the process of policy formation. However, except for the concrete interactive process of labor policymaking by structural and active system, we still can observe the invisible cultural effects which articulate the relationship between different cultural models and the formulation of institutions.

In terms of Chinese cultural analysis, we see the shadow of Neo-Confucianism and the patriarchal system affect different dominant boundaries and functions within the Chinese social-political structure. How do support the internal mechanisms necessary to construct the harmony system within the Chinese social-political structure? 
What are the concrete influences which guide the model of operation in the formulation of policymaking? In order to answer these questions, this paper pays great attention to contextualize a discussion of the reciprocal penetration and articulation between Neo-Confucianism thought and the patriarchal system in the external social-political circumstances of policymaking process.

\section{Political Socialization}

Political culture can be seen as a set of attitudes and motivations bringing about overt patterns of political behavior. As Dowse and Hughes (1972: 184) mentioned that the political system is embodied in a nexus of family and kin, family socialization has a direct impact upon the political behavior of members of the society. In Chinese society, most political behaviors were based on the realisitic pursuit of material interests by people lacking much sincere commitment to Neo-Confucian principles (Dowse and Hughes, 1972: 167). Basically, the traditional ideas of Neo-Confucianism refer to two dimensions of which the first focuses on the internal development of individuals. The second dimension is the manifestations of these principles in institutional structures, as in the concept of filial piety, and this shows the actual forms and patterns of interactions between diverse actors and sectors within Chinese social-political structure. The interactive structure was influenced and designed by the direction of systematic Neo-Confucianism principles. In the following section, I concentrate on the construction of political socialization and state ideology which potentially constructs the top-down political structure to stabilize the formulation of policies circumstance in Taiwan and prevent controversial policy disputes and changes within diverse organizations.

Every political system is embedded within a particular pattern of orientations to political actions (Dawson and Prewitt, 1969: Rush, 1992). Therefore, political socialization is a process of "enculturation" and "ideologism" between individuals and the social-political structure. That is to say, agencies of political socialization will become the "bearers" of the cultural values which formulate the enculturation of individual political behavior and the ideologism of the constraints upon the whole operation within the political structure. In the different cultural transmission creates the discrepant expression of power structure, for instance, in comparison with the Western society which defines power as positive "participation" in the process of labor policy decision-making. In Chinese society, the Confucian parental governance sees that power as the epitome of non-decision-making (Yoon, 1998). All of these mechanisms might induce obligation and systematic legitimization (Rush, 1992). The mechanisms of political socialization replace fear as a way of maintaining citizenship through the educational loyalty and obedience. In Mosca's (1939: 70-71) analysis, there are different constructions of state's ideology of doctrines and beliefs in the earlier societies. According to this conception, Thompson (1990) recognized ideologies can be regarded as "systems of thought and beliefs" or "symbolic systems" which pertain to social action or political practice.

We can see that the formation of state ideology provides specific functions which put the ruling class in a dominate position and cover up the internal contradictions and conflicts within the social-political structure. In considering the importance of the state ideology, it is necessary to take the further step of asking how to formulate the state ideology in Taiwan and how this functions in the formation of political or policy processes. In order to answer these questions, we must concentrate on the most important traditional cultural mechanisms which operate between Neo-Confucianism and the patriarchal system in shaping the modern social-political structure of Taiwan.

\section{The Articulation between the Social and the Political Systems}

This paper demonstrates the function of articulation in the social-political dual system and explores its effects on the process of policy formulation. The first dimension deals with the influence of Neo-Confucianism in shaping political stability and the significant ways in which Neo-Confucianism creates an official, mutually supportive system in political structure of Taiwan.

\section{Insert Figure 1 Here}

As the basic structure is composed of distinctive networks spread out from each individual's personal connections. There is a different process of social integration between hierarchical clan systems. The extension from the family plots is seen as "private" to many clan hierarchies in the structural social system. It is important to discuss the multiple levels of analysis levels and to clarify the articulation that exists between Neo-Confucianism and the patriarchal system in the social-political sphere. In contrast, the other dimension concentrates on how the patriarchal system invisibly suppresses the oppositional social forces which emerge in the civil society. In addition, how the fusion of the two systems creates the harmonious and systematic manipulation of circumstances in policymaking process of Taiwan. Nevertheless, the separate investigation of these subsystems generates a gap between the individuals, family system and the governmental system, for there 
still are many levels of analysis, such as kinship and clan, which could be excluded from the model of dichotomous analysis model.

\section{Neo-Confucianism: the Formation of a Harmonious: Ordered System and Systematical Legitimate Domination}

When we see men of worth, we should think of equaling them; when

\section{We see men of a contrary character, we should turn inwards and}

to examine ourselves. (A1)

(Confucian Analects)

The above quotation displays an illustration of the basic social-political attitudes of Neo-Confucianism which pay attention to internalize rites and self-examining within the traditional Chinese structure. In the following section will demonstrate how the Neo-Confucianism principles transmit the construction of the ordered system and create the interactive structure within the process of labor policymaking. There is a general belief within the Neo-Confucian tradition that harmony is the result of finding similarity and common benefits. Any purposeful exaggeration of possible clashes will generate disorder and a loss of mutual benefits within the political sphere. Weber (1965) discussed the casual relationship between the spirit of Christianity and the western development of Capitalism. In a similar context, many of Taiwan's researches (Chang, 1980; Du, 1989; Yu, 1989) have paid attention to the interrelations between Neo-Confucianism and the recent political democratization and economic developments of Eastern Asia, including Japan and the "four dragons" (Taiwan, Korea, Hong Kong and Singapore). Therefore, as Hamilton (1997) said, Neo-Confucianism contains an elaborate ideology of familism and an equally elaborate ideology of stagecraft, which was supported by the elites of Japan, Korea and Taiwan. However, in Hamilton's $(1991$, 1997) view, he regardless of the change from Confucianism to Neo-Confucianism which corporate the Buddhism into the systematic construction and overemphasized the demonstration of the influence of Buddhism in Japan and Korea.

Neo-Confucianism brought up the ethical spirit as an ordinary doctrine and positively expanded it from the cultivation of oneself to the concrete constructions in social and political system. First, it could be argued that when Buddhism entered China, it was inevitable that Buddhism's thought would fuse with Neo-Confucianist thought and gradually formulate the internal transformation of Neo-Confucianism. The transformations between those paradigms have continued to influence East Asia societies, especially, in their political systems. Secondly, it could be doubted that Buddhism became the important indicator for the state. There is a mutual influence between Buddhism and Neo-Confucianism, however, Buddhism did not become the central political bearer in Chinese society. The developmental state's ideology is absolutely established on the hybrid construction of internal Neo-Confucianism and external Legalism in the political system. Therefore, the same mistake was made in Eisenstadt's (1996) view, as he confused the explanation of Neo-Confucianism with that of the functions of Buddhism and the mistake comes from the neglect of the transformation religious and political thoughts in historical development in Asia societies.

Additionally, many articles have discussed the relationship between cultural values and economic development, for instance Granovetter $(1985 ; 1992)$ argues that this has at least as much determining effect on the structure and behavior of business groups as the cultural norms and values of Neo-Confucianism. Exclusive economic development, more recently, it can be seen as involving a dynamic interplay between the intellectual, social, political, and economic currents of East Asia, when we pay particular attention to the cultural implications of the descent of political authority and the rise of democratic development in East Asia.

In the process of cultural transmission, we can identify a "Confucian ethic" based upon hierarchy, discipline, control and motivation. The pervasive concept of authority as a political structure, provided the individual with an "inner" psychological base which could through the "self-strengthening" of self-cultivation be fortified against the onslaught of those "fears and anxieties" which flow partly from the activities of the "outer" political hierarchy. The seriously Neo-Confucian individual sought to replace them with an "internal ruler" and thus autonomously to decide his moral obligations (Metzger, 1977, Kahn, 1979, Han and Ling: 1998). Essentially, the Chinese folk society has an attitude of anti-litigation and values the harmony of an honored position, even if this harmony is apparent and surpasses the realistic and public conflicts. Furthermore, political attitudes are inclined to negatively and tenderly shaping political affairs. In contrast, in the Western democracies, they reflective political culture asserts that its members should be provided with the property of subjective orientations. Almond and Powell's (1978) research indicated, the operation of democracy is highly dependent on a participant political culture. They have great confidence in their capability to participate in the policymaking process, however, the cultural divergence leads to the spiritual deficiency in the political and policy domains of participation. 
Firstly, the apparent influence of Neo-Confucianism in traditional Chinese society was well equipped to contribute to the legitimizing function of the new discourse. This can be traced back to the earlier Han dynasty (206 B.C. to 220 A.D.) and the Chin dynasty (1644 to 1911 A.D.) in China, Neo-Confucianism was elevated to the status of the state ideology. The Confucian cultural system was then integrated with the political structure, which had a strongly legalistic character. Thereafter the mutual interpenetration of culture and politics was significant in transforming the fundamental social-political reality from imperial China to modern Chinese society. From the Han dynasty onwards, Neo-Confucianism became what can be called institutional Neo-Confucianism as a result of the mutual penetration of the cultural system and the political structure (Ambrose, 1997). However, the term institutional Confucianism refers to an institutional-cultural complex and it maintains that there are links between the keystones of the state governance, the imposing bureaucracy and the Chinese gentry. This historical development reveals Neo-Confucianism to be an instrument of ideological politics and effectively articulates the diverse sectors of the political structure. By and large, Confucianism has some principal regulations, such as self-cultivation, regulation of the family, social civility, moral education, well-being of the people, governance of the state and universal peace, all of which provide a general framework for our consideration $(\mathrm{Tu}, 1997)$. We can find the related connections between the traditional society and modern Taiwan's society.

In addition, FU (1986) recommends Arthur Jones's view, they commonly recognize that the ethic of Confucianism dominate the regular system which asserts certain sequential properties, such as obedience to authority, the loyal of family, diligence in labor and respect for one's elders. As Dore's (1985) research indicates, the ideal of benevolence denotes the paradigm of behavior of the leader. The ethic of Neo-Confucianism saturates the institutional system and gradually promotes both the governmental system and mass laboring individuals or organizations to accept the given social-political value system. Whether from the viewpoint of power or duty, the state bureaucracy had a positive interventionist or transformative stance to maintain the security of the political structure.

The Neo-Confucianism thought influences the formulation and choice of labor policies in the model of constitution. How and why does Neo-Confucianism indirectly shape and influence the formation of labor policymaking? In order to answer this question, we must again trace the historical development of Neo-Confucianism back to the Song Dynasty. There were two distinct shifts in this respect; one prevailed in ideological politics and the other permeated civil society. The enormous bureaucratic intellectual thus became an extensive arm of the state apparatus in the Chinese political system. In traditional Chinese culture, it is believed the principle of "Excellence in scholarship leads to officialdom" which indicates the way of intellectuals and simultaneously constructs the symbiotic relationship between scholars and the official system in the political bureaucracy. The symbiotic model intensifies the corporation of intellectuals to generate structural attachments in the political system.

As Bao (1989) indicates, the principles of human relationships and the majority principles of righteousness between monarchy and courtier in Neo-Confucianism, encourage the social responsibility of the intellectuals in the society to pledge their collective loyalty to the monarchy. The intellectuals' knowledge of the power they hold will inevitably be absorbed into the immense state apparatus. Part of the role of scholars becomes the extension of the governmental hand to legitimatize their negotiable channels between the central governmental system and civic society. This kind of ideology assimilates the value system of the intellectual either directly or indirectly and it provides a pathway to construct the linkages between intellectuals and the state bureaucracy.

Therefore, the same stipulation as that of Nosco (1984) and Chang (1996) said that "the Neo-Confucian view of political order by and large broke down into two categories: the way of governance, which stressed the moral-spiritual force of personality. The other is the institutional measure of government which focused on the institutional forces that go into making a political order". All political phenomena have the same influence in the modern society of Taiwan, and the Neo-Confucianism appears to have made its mark on Chinese society with its concern for hierarchical relationships and its emphasis the harmony within the home as the basis for harmony within the state apparatus.

Neo-Confucianism can be seen as a philosophical insight, a political ideology or a storehouse of popular values which are inclined to entirely infuse from the social structure into family organizations. However, since the Han dynasty began to assert that it is necessary the philosophical Confucianism has been made distinct from the politicized Neo-Confucianism. From the traditional to the modern society, as Tu $(1984,1989)$ argued political leadership rests upon the recognized excellence of the ruler: "authority is achieved by superior personality traits". Therefore, in the Confucian world order, officials are the fathers and mothers of the people. The people, in turn, are their filial child-subjects. The Analects instructs the state to "act as if you were watching over an infant 
(Grazia, 1973; Han and Ling; 1998). The systematic operation constructs the legitimate authority which emerges cultural factors also play a major role in affecting how groups are perceived and what policy options are conceivable. Therefore, within each policy sector certain beliefs tend to dominate the policy-making process and provide the parameters for acceptable options (Smith, 1993). Within the context of this discussion, it shows that the function of Neo-Confucianism hierarchicalize the political, and policy systems and the civil society. It simultaneously encourages Taiwan's labor policy to follow the model of policy decision-making forward to political state-Corporatism. On the other hand, it enhances laborers to strive for harmony and tacitly approves the present policymaking of state's domination.

\section{The Construction of Institutional System: Social Order}

How can we demonstrate the relationship between institutional constructions and informal constraints? The institutional theorist North's $(1984,1991)$ argument suggests that institutions consist of a set of constraints on behavior in the form of rules and regulations. Therefore, the relationship between institutional constraints and ideal regulations mutually modifies the formation of the social order system and identify the moral principles governing human action in related to those governing the universal order.

Consequently, many institutional channels provide the function of articulation between the ideology of the state and civic society, for instance the educational system plays an assimilative function within the fused system. In Carnoy's accounts $(1974,1990)$, notions of correspondence, cultural reproduction, and contradiction are important in developing an analysis of the role of education in social transformation. In light of Marsh's (1961:13) case study of 572 governmental officials shows the recruitment of the bureaucracy can be categorized three pathways, there are the preferred path, the examination system, and purchase (donate money). These ways through an occupation creates the specific political strata and determines the official-intellectual system. In traditional civil society, the examination system becomes the universal channels of social mobilization, therefore, the intellectual is absorbed into the political system by virtue of systematic examinations. The mechanism of ethic principles and personal loyalty for the king shifts the social responsibility and historical mission of the intellectual to servicing the monarchy.

The detail investigation in Confucian's educational assertions, $l i$ becomes the central concept of the individual moral system. $L i$ refers to the total amount of moral excellence and it could be taken to mean propriety or correct behavior in a moral sense and which is inseparable from the ideas about human nature, ethics and the ideal social and political order. $L i$ was desirable because it encouraged people to recognize and fulfill their responsibilities toward others (Ebrey, 1991). Therefore, there is a great social and political construction by the authorities to decide what constitutes $L i$ and how to govern the state apparatus and civil society through it. In the following section, I construct the internal transitive mechanism in Figure 2 to stipulate the policy of ideal transformation. $\mathrm{Li}$ is a starting point in the conceptual system of Neo-Confucianism. The process of overcoming one's own desires and recovering $L i$ becomes benevolence, the central point of which is the pathway of magnanimity. This is a summation of Confucian teachings, which is true to its principles and benevolent in their application towards others in the moral system.

\section{Insert Figure 2 Here}

The path of magnanimity suggests two dimensions which are self regulation and esteeming monarchy. At the moral level, self- regulation focuses on self-civilization in cultivating the heart and nature in personal daily life and consensual social rituals. In contrast, esteeming monarchy emphasizes an absolute loyalty to the monarchy. Furthermore, these principles pass through the educational system of state ideology to feed back into the different stages on individuals. Most Neo-Confucian thinkers whose political attitudes were integrated into a cohesive metaphysical system were likely to have a highly complex and ambivalent attitude toward centralized political authority (Wood, 1995: 20). Therefore, the ambiguities of moral choice explicitly provides the means to realizing moral values which might have been perceived as exercising such profound influence on the levers of political power, and this occurs in the hierarchical relation between the cosmos, the official pantheon, and human society.

Under this conceptual construction, Neo-Confucianism governance underpins the "three bonds" of superior-subordinate relations. The three bonds in human relations (including the relationships between ruler and subject, father and son, husband and wife) are the infrastructure of moral order and the three linkages directly enhances the construction of the order system. The five constant virtues (including mother's benevolence, father's righteousness, elder brother's love, young bother's respect and son's filial piety) and the norm of etiquette become the core of traditional culture.

Essentially, The three bonds and The five constant virtues are standardized the relationship of equal-difference in 
human relations which arranges the unequal and non-reciprocal relations in the order system from the political hierarchical system to social life. The Neo-Confucianism believes formulate the role pattern in their mutual dyadic relations, and this constructs the theoretical base of submission to the political manipulation. From those patterns of relations in traditional culture, restraints will construct a functional form of social control and order within the interactive system. Those internal personal standards are modified by the long-term educational system from the socialization of children up to adulthood. By way of the educational system cultivated loyalty and patriotism in the social-political system. Even unconsciously, the educational system potentially establishes the principle of the harmonious relations between role positions in the political domain. The rule "to obey the authority and the most precious is harmony" embodies the discipline involved in the process of individual development. The continuity process from the basic social units to public educational institutions collectively constructs the process of individual political socialization.

\section{Confucian's student Mang-I-Tze asked about filial piety.}

\section{Confucian answers: Don't disobey, not opposing and not avoiding.}

\section{(Confucian Analects)}

The similarity vestiges traced in Smith's (1996) investigation, recognizes the ethical teachings concerning political loyalty, filial piety, female chastity and justice or righteousness, in relation to the "Confucian" social structure, in which these teaching have become embedded. From those processes the harmony of social order is created, as found in our real lives, from the long-term assimilation of the constraint of morality. The commonality of the term used in society of Taiwan "to turn big problems into small problems and small problems into no problem at all" becomes the principal norm of daily life which is used to prevent conflicts between individuals and organizations. The greatest value is to be friendly and to maintain the outward harmony with other people or organizations, especially the person in the authoritarian political structure. This systematic maintenance constructs a subordinate relationship which makes the oppositional political subject vanish different forms of political subordination.

According to feudal ethics, the principles of human relations within Neo-Confucianism asserts the five ethics (lun in Chinese) which can almost be seen as five social dyads which indicate the regular mutual interactions within the human behavior system to cover the whole sphere from private relationships to public orders. Moreover, the key assertion focuses on the behavior of reciprocal coordination in the interactive relations of five social dyads. The function of the five ethics constructs the standard which guides every person to strictly obey their proprieties and take responsibility for their structural positions in social-political system. A concept different from Weber's stipulation (1964), he emphasized that the Neo-Confucian individual personality lacked "tension with the world", as it was still characterized by moral tension in that it was dominated by an anxiety-ridden need to depend highly on one's social superiors for authoritarian guidance. Therefore, the authoritarian guidance provides the mechanisms needed to settle peoples' emotion. Through the construction of a standard the internal frictions and conflicts within the social-political system vanish. In the view of Wood (1995), the contribution of Neo-Confucianism from the history of Chinese to modern Chinese society political thought, in real society therefore, lay in the way in which they incorporated their views on political authority into metaphysical explanations of the universe and the regulation of life. These principles shaped the nature of the universe, in which moral values were held to be absolute and unchanging.

On the summary, the ethics of Neo-Confucianism create traditional restraints within the Big traditional sphere of the ruler class and bring about the influence of moral teaching to the Small traditional sphere of regular life in civil society. In certain regions of Chinese society, the ethics of Neo-Confucianism become the predominant source of power used to harmonize the internal principles into the social-political structure and to give assistance for the ruling class in transmitting and putting into practice their thought from the Big traditional sphere to the Small traditional sphere. The rites of Neo-Confucianism affirm and exemplify certain norms of human conduct, including governance. These fundamental assertions represent a basic constitutional order, correlative in importance to individual and public morality.

On the whole, Neo-Confucianism thought provides a legitimate form of domination from the top-down dimension in policy circumstance. Furthermore, in the real manipulation of political operations by social construction, the dimensions of the top-down model become weaker in permeating the values, and beliefs systems of the civic society. Thus, there is an urgent need for the bottom-up system to give underpinning their systematic operations within the policymaking process. This is underpinned by the typical Confucian virtues which see filial piety and loyalty as a supportive formulation for superior authority at the same time. From a sociological perspective, Neo-Confucianism initiates the rule of politeness and benevolent administration which 
becomes the main method of social control. However, this is insufficient to manipulate the development of the state apparatus and combine with the thought of the Legalism School to settle down stable operation. The dual operative system in traditional Chinese society, the hybrid of internal Neo-Confucianism and external the legalist school become the linkage between the Big and Small traditional sphere. In the following section, this paper will shift attentions to a discussion of the patriarchal system which provides a bottom-up function in the systematic maintenance and operation of policymaking.

\section{The Patriarchal System: a Hybrid Concept}

From this discussion of traditional concepts, we can see that most research on the patriarchal system has been inclined to indicate that gender segregation and labor marginalization are embedded in the consequences of the interaction between patriarchy and capitalism in contemporary society. Following part of Weber's illustration in Economy and Society (1968), Barrett (1980) and Eisenstein (1981), Mitchell (1986), stipulated that patriarchy provides a systematic control and order, while capitalism provides a system of economy. The modern labor market formulates the dual systems which are based upon patriarchal relations. Walby $(1986,1990)$ and Witz (1992) defined patriarchy as a system of interrelated social structures through which men exploit women. In this context, the concept of patriarchy remains a historical descriptive term which refers to the expressions of male domination within the society and the way in which women come to terms with an inferior gender status, it broadly provides a gender-based concept of the domination.

The causal relations between patriarchy and capitalism, as Walby (1990) elucidates, imply that patriarchal relations pre-dated capitalism, and were not created by them. The rise of capitalism was a factor in the development of a new form of patriarchy, but not in changing its basic structure. In the same context, Mies (1998) contends that the structuralization of capitalism- patriarchy is not only displayed in the predominant relationship between men and women but also in the different dimensions within the social and political structures of modern capitalism. To a different extent, patriarchal influences exclude the possibility of social and political participation in labor policy among various historical developmental periods.

\section{The Exclusions of Women in the Patriarchal System}

The construction of the patriarchal system is a systematic mechanism of the social and structural exclusion of women's participation. The patriarchal model of discussions between the private (family organization) and public (government) domains is developed in much feminist research. They contend that women's structural position in society has never been a prominent issue in Western or Eastern societies. The problems of gender segregation and long-term neglect of women's issues make them systematically excluded from political participation in the labor policy process. The exclusionary strategies are said to be based upon a private form of patriarchal system in which women were controlled by being excluded from the public sphere.

The power of capital precluded the successful maintenance of the exclusionary mode, certain except forms of patriarchal power and resistance (Walby, 1990). These institutional forms of exclusion are structured in diverse settings. Basically, the formative process also includes the definition of husband and wife as a new unit. A man is granted exclusive sexual access to his bride, and usually women are incorporated into the family system. The exclusive system reduces the internal conflicts between men and women in gender issues, in contrast to the enhancement of peaceful labor policy circumstance. In the following section, this paper will extend the discussion of patriarchal system to the public sphere. Based on the historical and structural stipulations of the long-term study women's movements and the study of gender-based legislation in labor policy reveals their subordinate and marginal positions within different social and political aspects of labor policy in Taiwan. This exclusion can be distinguished from the dimension of the institutional designs which emerge from policy issues in agenda-setting and the decision-making process.

Therefore, the patriarchal system can be traced back to the influences and supports of different levels of the complex political structure. As Weber (1946) suggests, it is not only "patriarchal power especially is rooted in the provisioning of recurrent and normal needs of the workday life" but also "the patriarch is the natural leader of the daily routine". The construction of patriarchal system becomes a political concept which can be compared with charismatic authority and the bureaucratic system. I want to extend that both Walby (1990) and Witz (1992) place insufficient emphasis on the original term "patriarchy" to the construction of patriarchal system as it was used in Weber's (1964) interpretation. The evidence is that Weber's concept, in addition to placing the relationships within the gender-based domain, could also refer to the extension of boundaries around a systematic political structure.

Therefore, there are so many different forms of patriarchal patterns and relationships to embed between diverse private and public fields. Under patriarchal domination, the legitimacy of the authority which limits the 
patriarchal powers of control, is derived from social "norms". As Weber said, the belief is rooted in the concept of filial piety, in the close and permanent living together of all dependents of the household which creates an external and spiritual "community of fate". Therefore, the two basic elements of patriarchal authority are piety towards tradition and piety towards authority. The power of the former also constrained the master and hence benefited the subjects who had no formal rights (Weber, 1968: 1008). In Weber's view, the patriarchal system could not limit the concept in both the domestic boundary and gender-based issues. This provides us with an extension to demonstrate it's political meaning and imagination which wields the potential construction of political power.

\section{The Politicalization Extension of the Patriarchalism}

In Weber's theoretical framework, patriarchal authority exercised by a particular individual and it is designated by a definite rule of inheritance. Following Parsons' (1964) statement, the original patriarchalism is related to this in that the authority of the patriarch carries strict obligations to obedience only within his own household and by the household of the individual who carries out the governing functions. There is an explicit description provided by Shephard (1994) who evokes an image of the chains and links between the family system, the government and the emergence of original authority.

In Shephard's (1994) analysis, the family becomes another reflection of the cosmic harmony system, providing the pattern for political and social relationships. Therefore, the patriarchal system provides the place of culture in the construction of social order in general social life, and in the order-maintaining and order-transforming functions of culture in particular within the household. In "Economy and Society" (1968), Weber asserts that the logic of patriarchal authority has to go beyond and transmit it's internal sphere from the original family to the formation of political authority. Therefore, in Weber's view, the traditional Chinese culture is an extreme example of the patriarchal system which displays the specific patriarchal characteristics within the entire political structure and organizations in the public sphere.

In England, Schochet (1975) indicated patriarchal justifications of obedience to political authority were regularly and officially taught by the churches of Western society. The simple requirement to "Honour the father and the mother" was expanded to include loyalty and obedience to the king and all magistrates, as well as to masters, teachers and ministers (Schochet, ibid: 50). The power of the order system was seen as inherent and God-given and this received the support of the legitimate rules of the Western society. Therefore, political obedience was due to the authority of the leader because of the extension in his fatherly rights. The political order was organized in terms of familial symbols, which meant that political authority was identical to the rule of the father or patriarch over his family. Above all, the statements explicitly implied that government and monarchy were natural institutions in the historical and political development. The same context of patriarchal relationships existed in the traditional Chinese social and political systems. Therefore, the doctrines of patriarchal system were a defense of political authority and they had an interdependent relationship with the family and government systems. In terms of Schochet's statement, there are many different types of patriarchal notions, which leads us to elaborate upon the historical development in penetrating political and legitimate authority. The reciprocal identification between paternal and regal authority commonly allows the complete application of the familial symbols to the political system.

Therefore, the patriarchal system existed universally in diverse societies and its appearance depends on the particular situation. As we know it strengthens the belief that "to transform family filial piety to monarchy loyalty". Those concepts assist the extension of the filial concept from the family organization to governmental authority, whilst, at the same time assimilating the idea of patriarchal domination into systems of governmental operation. On the other hand, the patriarchal system supports the family system and systematic linkages between the family and the political structure. The patriarchal system concentrates on the formation of submission as being unrestrained in the natural consciousness of its internal members. This means that it is not easy to disappear in going along with the changes in the political structure. From the submission of filial duty, we see the extension of powerful authority in the patriarchal system. As Chu (1961) and Hamiliton's (1987) argue, the core of the Chinese patriarchal system is filial piety, which becomes an internal mechanism to formulate a dominant principle within the social-political structure. Consequently, from my investigation, we see that the patriarchal system establishes converse relationships from bottom-up trail to construct the dominant structure.

In the Chinese society, the domination of the patriarchal principle regulates the boundaries and the role's positions within the family structure. Filial piety becomes the internal mechanism and basic moral rule which strengthens the structure of the order system. Until now, this still explicitly displays the principle of sincere submission and the infrastructure of moral order within Taiwan's social and political structures. Moreover, the 
idea of filial piety provides a fundamental means of transmission within the order system from the family field (the relation between father and son) to the political structure (the relationship between upper officials and petty official). At the same time, the filial obedience will be transformed into personal loyalty and will stride across the regulative moral space between the private and public spheres.

To summarize the above discussion, the patriarchal propositions show to be that, first, family authority is natural, divinely sanctioned, and - in its pristine form--- absolute and unlimited. Secondly, political power is seen as identical to the power of the father. The function of assimilation intensifies the everyday life discipline because people living together will always need a formal government and because the children have grown accustomed to patriarchal authority. The logic of legitimate authority is based highly upon the patriarchal system and aims to integrate the social and political structures. The traditional Chinese adage that "the huge filial piety is transformed from the filial piety of the family to monarchy loyalty of the country" becomes a paradigm which displays the context of order system in asserting that loyalty becomes the extension of filial piety from the private sphere to the political structure. Filial piety becomes a transitive mechanism with which to legitimize both top-down and bottom-up power constructions within the policymaking process. Therefore, there is an interactive existence between the reciprocal transformation in traditional ideological operations and the construction of political institutions.

\section{Conclusion}

As Jin and Liu's (1984) analysis, Neo-Confucianism provides a social and political mechanism within which to maintain the super stable structure in different space-time location. Neo-Confucianism is seen to provide diverse stable mechanisms which echo the findings of Zhang's (1999) investigation. These mechanisms strengthen the obligation of the subject to obey the ruler and at the same time to obey the universal moral order. By virtue of the three bonds and the five consent virtues rested the order system from private to public system. Therefore, this apparently provides another consideration which focuses on how obedience is ensured by consent, not coercion; it is voluntary, although also mandatory. The legitimation of the top-down model is based on simply accepting it as a natural and unquestioned part of the universe. The embedded operation of Neo-Confucianism is similar to Lukes's (1974:23) third dimensional model of power, which considers the possibility of particular demands or conflicts becoming political events within the political system, in contrast to the power formulates the legitimation of supervise potentially.

The Analects of Confucius provided much of the basis for this common ground and its concerns were more with human virtues and excellent government. Sacrificial rituals remained important, but because proper performance of such rituals, especially by rulers, was one of the most effective means of attaining an orderly society and cultivating morality among its members. Here organizations would act as intermediaries and linkages between the family and the state, which would exist as a form of political infrastructure, with formal channels of communication leading upward to policy-making levels at the top and in the center. The beliefs of Neo-Confucianism provide a bridge to connect internal personal regulation and the externally institutional regulations in political system. The different stages of systematic connection formulate the coordination and juxtaposition within the internal institutional operations. At the same time, the demonstration of educational systematic design which provides the necessary mechanism to harmonize the internal conflicts, relies highly on a personal transcendence which affirms the communal basis of human nature. Thus Neo-Confucianist thought provides a complete value system which helps the construction of a universal value consensus for individual actors. The internal mechanisms involved help to avoid the isolation between civic society and the governmental system.

The same concept of the more from the family organization to the governmental system implies the primacy of loyalty to the state over loyalty to family relations. Moreover, Neo-Confucianism has become codified through state patronage of classical scholarship which is linked to public morality. The priority given to the state over family loyalties is one sign of this. Other signs are the coordination of those relations with hierarchies of nature such as the triadic order of Heaven, Earth and Humanity (De Bary, 1998:125). Adhere to disciplines was good for the participants' moral development and at the same time improved the harmony and order of the policy decision-making process. In the political field and the civility of social life, this harmony can be seen as an immortal truth. Likewise, internal conflicts will injure the entire formulation of social harmony and social order, therefore, it is better to become reconciled immediately with the unstable condition of political behaviors. Above all, these discussions directly and effectively give demonstrate the effects of constructing the operation of the top-down model in the policymaking of contemporary Taiwanese political structure.

In the bottom-up model, Weber (1964) suggests that the patriarchal system is a prominent dimension of 
traditional domination. Therefore, in the patriarchal authority system, obedience to individual belonging orders does not mean submission to a general principle out of discipline and duty, but out of subjection and fealty. In contrast, the family organizations, the discipline of officials and the political structure of Neo-Confucianism all directly strengthen the patriarchal system. That is to say, loyalty to figures of authority is based on the concept of filial piety. Therefore, the conceptual subordination is assimilated from inside the person's mind and directly influences their social and political action in their daily life (Metzger, 1977). In the family sphere, the main principle is that children must yield to their parents' authority in the family. Similarly, the extension of the patriarchal system into the political system shows as the civil servant submits to the ruler and the lower rank civic servant is obedient to the higher ranking civic servant which becomes a political imagination of hierarchical bureaucracy within the political structure.

The basic moral of filial obedience is found in parallel as a prominent concept in both Neo-Confucianism and the patriarchal system. Therefore, the concept of filial piety formulates the internal mechanisms needed to articulate Neo-Confucianism and patriarchal system as different hierarchical systems of social-political structure. For this reason, from the private sphere of the family, the ideal order system smoothly extends the central values to individual political organizations and the wider social structure. This systematic bottom-up extension intensifies the principle of the patriarchal system and constructs a bridge between the private and public spheres of social-political structure. Under the systematic mechanisms of harmony and order, this reinforces the neutralization of internal conflicts within different levels of the policymaking process, especially the controversies over some specific labor issues. Those mechanisms strengthen and underpin Sabatier's (1993, 1998), Schon and Rein's (1994) concept of the "core beliefs value" of policy and prevent the possibility of generation in policy challenges or changes.

Overall, the above discussions have demonstrated the importance of maintaining harmonious operations in the processes of policymaking. The evidences emerge from the reciprocal permeation of the state ideology, the assimilation of Neo-Confucianism thought and the patriarchal system. The concept of ordinal ethics performs certain functions which influence the specific policy process, that contrast with those found in Western societies. In the integrated political culture, these internal mechanisms mean that the process of policymaking can be seen as given process in the social-political structure. Under the patriarchal political culture, there is no apparent difference between the political, social and religious domains. Thus on the one hand, modernization has taken place in Taiwan since the 1950s, which has resulted in the fundamental transformation of the combination of state Confucianism and the patriarchal system. However, on the other hand, the long-term assimilation of Neo-Confucianism and the patriarchal system continues to have a potential hand in shaping the harmonious system within the diverse levels and relationships of virtual labor policymaking in Taiwan.

\section{References}

Alexander Jeffrey and Seidman Steven. (Eds) (1990). Culture and Society: Contemporary Debates. New York: Cambridge University Press.

Ambrose Y.C. King. (1997). State Confucianism and its Transformation: The Restructuring of the State-Society Relation in Taiwan. In Wei-Ming Du. (1997). Confucian Traditions in East Asian Modernity. Cambridge: Harvard University Press.

Andrew Vincent. (1992). Modern Political Ideologies. Oxford: Blackwell Press.

Archer Margaret S. (1996). Culture and agency: The Place of Culture in Social Theory. Cambridge: Cambridge University Press.

Bao Zun-Xin. (1989). Critical and initiation. Taipei: Lian Jing Press.

Bary Theodore de. (1998). Asian Values and Human Rights: a Confucian Communitarian Perspective. Cambridge: Harvard University Press.

Bell Daniel. (1988). The End of Ideology. USA: Harvard University Press.

Bellah Robert N. (Eds) Religion and Progress in Modern Asia. New York: Collier Macmillan Limited.

Bennett Tony. (1998). Culture: A Reformer's Science. London: Sage Publication.

Bradely David. (1998). Equality and Patriarchy: Family Law and State Feminism in Finland. International Journal of the Sociology of Law, Vol. 26, P 197-216.

Carnoy Martin and Samoff Joel. (1990). Education and Social Transition in the Third World. Princeton: Princeton University Press. 
Coyle Dennis and Ellis Richard. (Eds) (1994). Politics, Policy and Culture. Boulder: Westview Press.

Crane Diana. (Eds) (1994). The Sociology of Culture: Emerging Theoretical Perspectives. Oxford: Blackwell Press.

Dowse Robert E. and Hughes John A. (1972). Political Sociology. Chichester: John Wiley \& Sons.

Du Wei-Ming. (1989). Questions of Neo-Confucianism and its' Development of third Period. Taipei: Lian Jing Press.

Easton.D. (1965). A Systems Analysis of Political Life. New York: John Wiley and Sons.

Ebrey Patricia Buckley. (1991). Confucianism and Family Rituals in Imperial China: A Social History of Writing about Rites. Princeton: Princeton University Press.

Eisenstadt.S.N. (1981). Cultural Traditions and Political Dynamics: The Orgins and Modes of Ideological Politics. British Journal of Sociology, Vol. 32, P155-179.

Elder Neil and Page Eward C. (1998). Culture and Agency: Fragmentation and Agency Structures in Germany and Sweden. Public Policy and Administration, Vol. 13, P28-45.

Faure Guy Olivier and Rubin Jeffrey Z. (Eds) (1993). Culture and Negotiation. Newbury Park, CA: Sage Publication.

Fei Xiao- Tong. (1992). From the Soil: The Foundations of Chinese Society. Berkeley: University of California Press.

Fu Pei-Rong. (1997). The Enter of Confucianists' World. Taipei: Yang Zhi Press Abercrombie Nicholas, Hill Stephen and Turner Bryan S. (Eds) (1990) Dominant Ideologies. London: Unwin Hyman Press.

Geertz Clifford. (1993). The Interpretation of Cultures. London: Fontana Press.

Gibbins John R. (Eds) (1989). Contemporary Political Culture. London: Sage Publication.

Gordon J.Schochet. (1975). Patriarchalism in Political Thought. Bristol: Western Printing Services Ltd.

Hamilton Gary G. and Biggart Nicole Woolsey. (1988). Market, Culture, and Authority: A comparative Analysis of Management and Organization in the Far East. AJS, Vol. 94.P 52-94.

Hao Chang. (1980). Neo-Confucian Moral Thought and its Modern Legacy. Journal of Asian Studies, VOL. 39, P260-275.

Heo Shin-Quan. (1996). Confucianism and Modern Democracy. Taipei: Philosophical Institution of Academia Sincia.

Hill Michael. (Eds) (1997). The Policy Process: A Reader. London: Harvester Wheatsheaf Press.

Inglehart.Ronald. (1990). Cultural Shift: In Advanced Industrial Society. Princeton: Princeton University Press.

Jin Yao-Ji. (1997). Chinese Politics and Culture. HongKong: Oxford University Press.

Leach Robert. (1996). British Political Ideology. London: Prentice Hall, Harvester Wheatsheaf. Press.

Levenson Joseph R. (1964). Confucian China and it's Modern Fate. London: Routledge and Kegan Paul.

Lichtheim George. (1967). The Concept of Ideology and Other Essays. New York: Random House Published.

Lukes Steven. (Eds) (1986). Power. Oxford: Blackwell Press.

Marsh Robert. M. (1961). The Mandarins: the Circulation of elites in China, 1600-1900. USA: The Free Press of Glencoe.

Mclellan David. (1995). Ideology. Buckingham: Open University Press.

Metzger Thomas. (1977). Escape from Predicament: Neo-Confucianism and China's Developing Political Culture. New York: Columbia University Press.

Mitchell J and Oakley A. (Eds) (1986). What is Feminism? Oxford: Basil Blackwell.

Mosca Gaetano. (1939). The Ruling Class. USA: McGraw-Hill Book Company Inc.

North Douglass. (1990). Institutions, Institutional Change and Economic Performance. USA: Cambridge University Press.

Pateman Carole. (1998). The Patriarchal Welfare State. In Joan B. Landes. (1998) Feminism: the Public and the Private. Oxford: Oxford University Press. 
Peterson Richard A. (1979). Revitalizing the Culture Concept. Annual Review Sociology, Vol. 5, P137-166.

Ping-Ti Ho. (1962). The Ladder of Success in Imperial China. New York: Columbia University Press.

Randall Vicky. (1987). Women and Politics. London: The Macmillan Press.

Rush Michael. (1992). Politics and Society: An Introduction to Political Sociology. New York: Harvester Wheatsheaf Press.

Sabatier Paul A. (1986). Top-down and Bottom-up Approaches to Implementation Research: A Critical Analysis and Suggested Synthesis. Journal of Public Policy. Vol. 6, P21-48.

-----. (1998). The Advocacy Coalition Framework: Revisions and Relevance for Europe. Journal of European Public Policy, Vol. 5, P98-130.

Sabatier Paul A., and Jenkins-Smith Hank C. (Eds) (1993). Policy Change and Learning: An Advocacy Coalition Approach. Oxford: Oxford University Press.

Schon Donald A. and Rein Martin. (1994). Frame Reflection: Toward the Resolution of Intractable Policy Controversies. New York: Harper Collins publication.

Seliger Martin. (1976). Ideology and Politics. London: George Allen and Unwin Ltd.

Skocpol Theda and Rueschemeyer Dietrich. (1996). States, Social Knowledge and the Origins of Modern Social Policies. Princeton: Princeton University Press.

Swidler Ann. (1986). Culture in Action: Symbols and Strategies. ASR, Vol. 51, P273-286.

Therborn Goran. (1980). The Ideology of Power and The Power of Ideology. Verso; New Left//books Ltd.

Thompson John B. (1990). Ideology and Modern Culture. Cambridge: Polity Press.

Tu Wei-Ming. (Eds) (1996). Confucian Traditions in East Asian Modernity. Cambridge: Harvard University Press.

Ungerson Clare and Kember Mary. (Eds) (1997). Women and Social Policy: A Reader. London: Macmillan Press.

Walby Sylvia. (1986). Patriarchy at Work: Patriarchy and Capitalist Relations in Employment. Cambridge: Polity Press.

-----. (1990). Theorizing Patriarchy. Cambridge: Basil Blackwell Ltd.

------. (1998). The New Regulatory State: The Social Powers of The European Union. British Journal of Sociology, Vol. 50, P118-140.

Wei-Bin Zhang. (1999). Confucianism and Modernization: Industrialization and Democratization of the Confucian Regions. London: Macmillan Press Ltd.

Wood Alan T. (1995). Limits to Autocracy: From Sung Neo-Confucianism to a Doctrine of Political Rights. Honolulu: University of Hawaii Press.

Woodiwiss Anthony. (1998). Globalization, Human Rights and Labour Law in Pacific Asia. Cambridge: Cambridge University Press.

Wuthnow Robert. (1987). Meaning and Moral Order: Explorations in Cultural Analysis. Berkeley: University of California Press. 


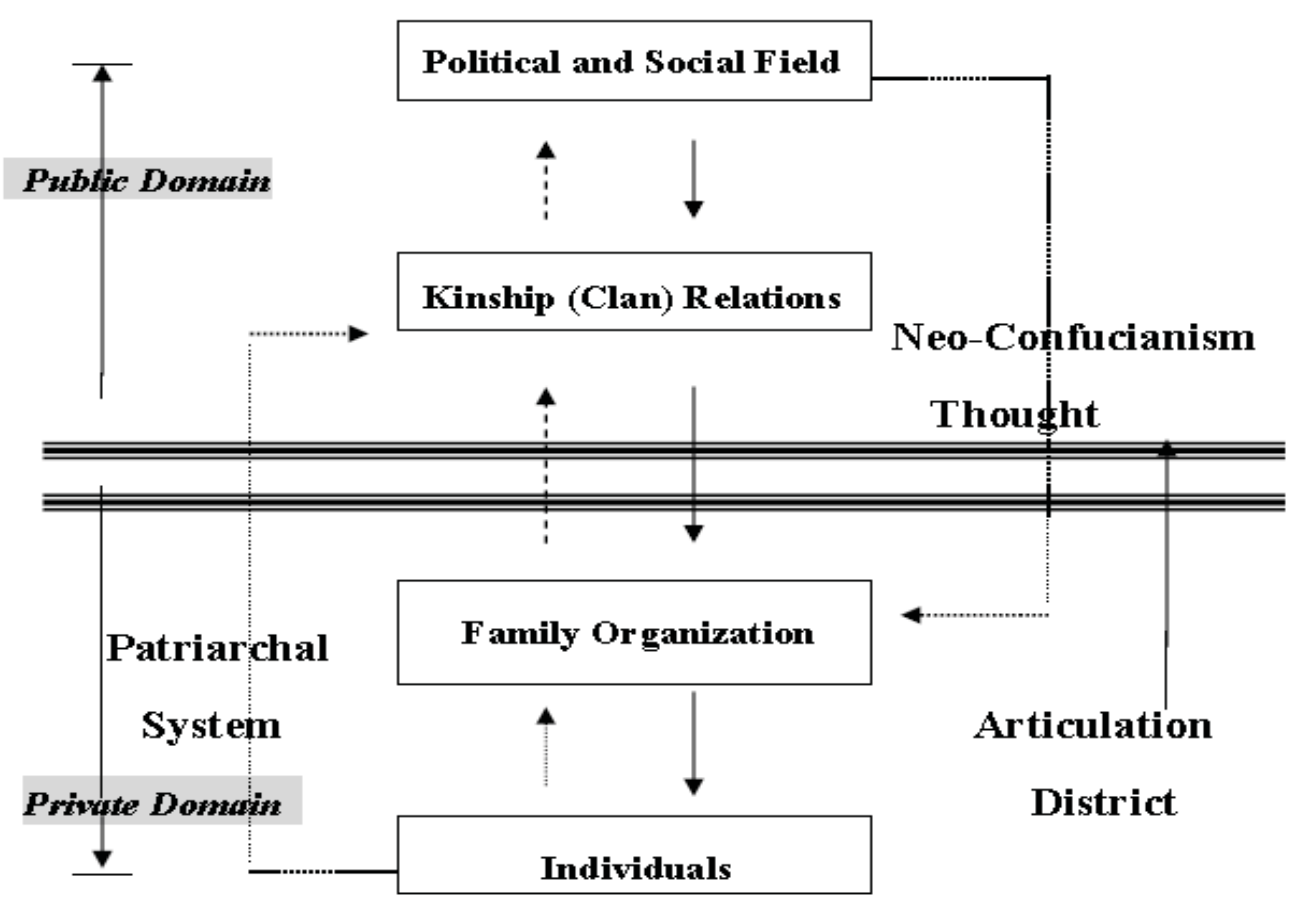

Figure 1. The Mutual Penetration and Articulation between Neo-Confucianism Thought and the Patriarchal System

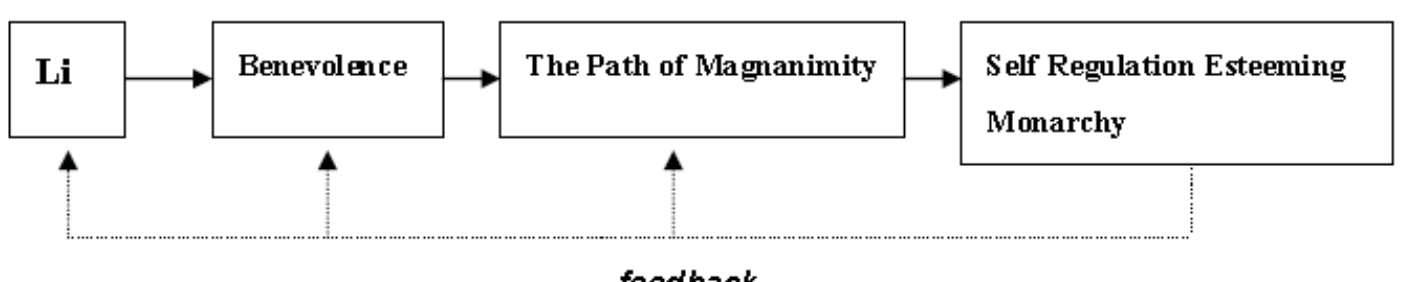

Figure 2. The Transformation of the Conceptual System within Neo-Confucianism 